\title{
EFEITO DA ESCARIFICAÇ̃̃O E LUMINOSIDADE NA GERMINAC̄̃̃O IN VITRO DE SEMENTES DE CAGAITEIRA (Eugenia dysenterica DC.) ${ }^{1}$
}

Effect of scarification and light on in vitro seed germination of (Eugenia dysenterica DC.)

\author{
Cristiano Martinotto ${ }^{2}$, Renato Paiva ${ }^{3}$, Breno Régis Santos ${ }^{4}$, Fernanda Pereira Soares 5 , \\ Raírys Cravo Nogueira ${ }^{6}$, Álvaro Augusto Naves Silva ${ }^{7}$
}

\begin{abstract}
RESUMO
A cagaiteira é uma espécie nativa do Cerrado com elevado potencial frutífero. Como suas sementes apresentam elevada variabilidade, sendo ainda recalcitrantes e dormentes, a germinação in vitro apresenta-se como uma alternativa para a propagação da espécie, além de permitir a obtenção de explantes juvenis para a micropropagação. Com presente trabalho, objetivou-se avaliar o efeito da escarificação e da luminosidade na germinação in vitro de sementes de cagaiteira. Sementes desprovidas do tegumento e sementes intactas foram inoculadas em meio MS e mantidas na ausência e presença de luz. Sementes desprovidas de tegumento germinadas tanto na presença quanto na ausência de luz apresentaram $86,25 \%$ e $88,25 \%$ de germinação aos 31 e 71 dias da inoculação, respectivamente. Após 150 dias de inoculação, plântulas provenientes de sementes desprovidas de tegumento, germinadas na presença e ausência de luminosidade, apresentaram $10 \%$ e $12 \%$ de anomalias, respectivamente.
\end{abstract}

Termos para indexação: Cultivo in vitro, cerrado, frutífera nativa, Myrtaceae.

\section{ABSTRACT}

Cagaiteira is a native specie of brazilian cerrado with high yield. Because it seeds show high variability, it is yet considered recalcitrant and dormant, the germination in vitro appears as an alternative for specie propagation, in addition to obtain juvenile explant for micropropagation. The present research aimed to evaluate the effect of scarification and ligth on germination in vitro of cagaiteira seeds. Seeds without teguments and intact seeds were inoculated in MS medium and kept in abscence and presence of radiation. Seeds without tegument germinated in the presence or abscence of ligth showed $86.25 \%$ and $88.25 \%$ germination at 31 and 71 days of inoculation, respectively. After 150 days of inoculation, plantlets from seeds without tegument germinated in the presence and abscence of ligth, showed $10 \%$ and $12 \%$ of abnormalities, respectively.

Index terms: In vitro culture, cerrado, fruit native, Myrtaceae.

\section{(Recebido em 3 de janeiro de 2005 e aprovado em 7 de agosto de 2006)}

\section{INTRODUÇÃO}

A cagaiteira (Eugenia dysenterica DC.), pertencente à família Myrtaceae, é uma espécie frutífera nativa do Cerrado. Apresenta propriedades medicinais, sendo também indicada como planta melífera, ornamental e para o reflorestamento de áreas degradadas, fornecendo, ainda, madeira para mourões e cortiça.

Alguns trabalhos relatam a existência de certo grau de dormência de origem tegumentar em suas sementes. Além da presença de inibidores, Rizzini (1971) cita um atraso na germinação de sementes de cagaiteira com tegumento intacto, sendo eliminado com a escarificação. $\mathrm{O}$ autor ainda comenta que, embora esse tegumento seja coriáceo, ele não é obstáculo para a passagem de água, porém, ao embeber-se, torna-se impermeável a trocas gasosas, podendo diminuir o aporte de oxigênio ao embrião, retardando seu desenvolvimento.

As sementes de cagaiteira são ainda, sensíveis à perda de água, não sendo capazes de manter alta viabilidade quando armazenadas hidratadas, independente da

\footnotetext{
${ }^{1}$ Parte da Dissertação apresentada à Coordenação do Curso de Pós-Graduação em Agronomia - Fisiologia Vegetal da UFLA, defendida em 06/08/2004, como parte dos requisitos para obtenção do grau de Mestre.

2Doutorando em Agronomia - Departamento de Biologia/DBI - Universidade Federal de Lavras/UFLA - Cx. P. 3037 - $37200-000$ - Lavras, MG cmartinotto@yahoo.com.br - Agência Financiadora: CAPES

${ }^{3} \mathrm{PhD}$, Professor - Departamento de Biologia/DBI - Universidade Federal de Lavras/UFLA - Cx. P. 3037 - $37200-000$ - Lavras, MG - renpaiva@ufla.b ${ }^{4}$ Doutor - Universidade Presidente Antônio Carlos - BR 262, KM480 - 35600-000 - Bom Despacho, MG - brenors@yahoo.com.br

${ }^{5}$ Doutoranda - Departamento de Biologia/DBI - Universidade Federal de Lavras/UFLA - Cx. P. 3037 - $37200-000$ - Lavras, MG fernandapereirasoares@yahoo.com.br

${ }^{6}$ Doutora - Centro de Ciências Biológicas - Universidade Federal do Pará - Rua Augusto Correa, 01, Guama - 66075-900 -Belém, PA-rairys@yahoo.com.br ${ }^{7}$ Biólogo - Departamento de Biologia/DBI - Universidade Federal de Lavras/UFLA - Cx. P. 3037 - 37200-000 - Lavras, MG - silvaan@hotmail.com Bolsista de apoio técnico CNPq
} 
temperatura de armazenamento, o que lhes confere um caráter recalcitrante (ANDRADE et al., 1997; MELO et al., 1998). Neste sentido, o cultivo in vitro dessas sementes apresenta-se como uma alternativa de propagação da espécie e como possível fonte asséptica de explantes para experimentos posteriores de micropropagação.

Conduziu-se o presente trabalho com o objetivo de avaliar o efeito da escarificação e da luminosidade na germinação in vitro de cagaiteira.

\section{MATERIAL E MÉTODOS}

O trabalho foi realizado no Laboratório de Cultura de Tecidos do Setor de Fisiologia Vegetal, pertencente ao Departamento de Biologia da Universidade Federal de Lavras (UFLA), Lavras, MG.

As sementes foram obtidas de frutos de cagaiteira coletados na região de Bom Despacho - MG em setembro de 2003.

Após serem despolpadas, as sementes foram lavadas em água corrente e secas parcialmente à sombra. Em câmara de fluxo laminar, foram imersas em álcool $70 \%$ por 60 segundos e, em seguida, em solução de hipoclorito de sódio 0,5\% de cloro ativo por 15 minutos, sendo então lavadas três vezes em água destilada e autoclavada.

O tegumento das sementes, conforme o tratamento (escarificado ou não), foi removido com o auxílio de um bisturi, sem danificá-las. Após a retirada do tegumento, as sementes foram novamente imersas em álcool $70 \%$ por 15 segundos e em solução de hipoclorito de sódio $0,3 \%$ de cloro ativo por 5 minutos, seguido de três lavagens em água destilada e autoclavada.

Sementes intactas e sementes sem tegumento foram inoculadas em tubos de ensaio contendo meio de cultura MS (MURASHIGE \& SKOOG, 1962), suplementado com $30 \mathrm{~g} \mathrm{~L}^{-1} \mathrm{de}$ sacarose. $\mathrm{O}$ meio foi solidificado com ágar $0,7 \%$ e o pH ajustado para 5,8 antes da autoclavagem a $120^{\circ} \mathrm{C}$, durante 20 minutos.

Após a inoculação, as sementes foram mantidas em sala de crescimento, em presença ou ausência de luz (irradiância de fótons de $30 \mu \mathrm{mol} \mathrm{m} \mathrm{m}^{-2} \mathrm{~s}^{-1}$ e fotoperíodo de 16 horas) e em temperatura de $27 \pm 2{ }^{\circ} \mathrm{C}$. A porcentagem de germinação foi avaliada aos 31, 71 e 150 dias após a inoculação, sendo também obtido o número de sementes germinadas com má formação de plântulas ao final do experimento.

$\mathrm{O}$ experimento foi realizado em esquema fatorial $2 \mathrm{x}$ 2 (com e sem tegumento e na ausência e presença de luminosidade), constituído de cinco repetições, sendo cada uma composta por 40 tubos de ensaio e cada tubo contendo uma semente. $\mathrm{O}$ teste de médias utilizado foi o de Scott Knott, a $5 \%$ de probabilidade.

\section{RESULTADOS E DISCUSSÃO}

Foi observado um efeito significativo da luz, da retirada do tegumento e de sua interação no total de sementes de cagaiteira germinadas in vitro aos 31 dias após a inoculação e no número de plântulas com má formação. Aos 71 dias após a inoculação, foi verificado efeito significativo apenas para a retirada do tegumento e para a interação entre a retirada do tegumento e a luz. Aos 150 dias de cultivo, não foi verificada influência destes tratamentos no número de sementes germinadas.

$\mathrm{O}$ efeito da luz se pronunciou apenas em sementes com tegumento e aos 31 e 71 dias de cultivo. Essa influência, provavelmente, está relacionada com a fotodegradação de compostos inibidores presentes no tegumento, acelerando a germinação. Alguns autores citam a degradação de compostos fenólicos pela luz (TIBURTIUS, 2004; ZIOLLI \& JARDIM, 1998).

Alguns inibidores de crescimento são substâncias de natureza fenólica, como o ácido salicílico, o ácido cumárico, o ácido clorogênico e a cumarina, as quais podem retardar processos de crescimento e desenvolvimento das plantas, como alongamento de raízes e caules e a germinação de sementes (VON-PINHO \& KIKUTI, 2004). Edwards (1973) observou, em café, que a presença de compostos fenólicos no tegumento controla a entrada de oxigênio na semente, diminuindo ou mesmo impedindo a chegada deste ao embrião, retardando seu desenvolvimento. Rizzini (1970) verificou que o extrato do embrião de cagaiteira em germinação e o extrato do tegumento de suas sementes são capazes de inibir fortemente a germinação de feijão-preto.

Sementes de cagaiteira desprovidas do tegumento apresentaram germinação superior aos 31 dias $(86,25 \%)$ e 71 dias $(88,25 \%)$ de cultivo com relação às sementes intactas (Figura 1). Rizzini (1971), estudando a germinação de sementes de cagaiteira, verificou um efeito retardador do tegumento na velocidade de germinação, proporcional ao grau de integridade deste. O mesmo autor relaciona esta dormência com a impermeabilidade do tegumento ao ar quando da embebição das sementes, o que causaria deficiência em oxigênio ao embrião.

Embora aos 150 dias de cultivo não tenha sido observada diferença estatística significativa para a porcentagem de germinação entre os tratamentos, a retirada do tegumento proporcionou uma germinação mais uniforme e mais rápida. Além disso, as sementes germinadas in vitro com a presença de tegumento apresentaram elevada ocorrência de plântulas com má formação, levandoas, posteriormente, à morte (Figura 2).

A interação do efeito da luz e da retirada do tegumento na porcentagem de plântulas com má formação está apresentada na Tabela 1 . 


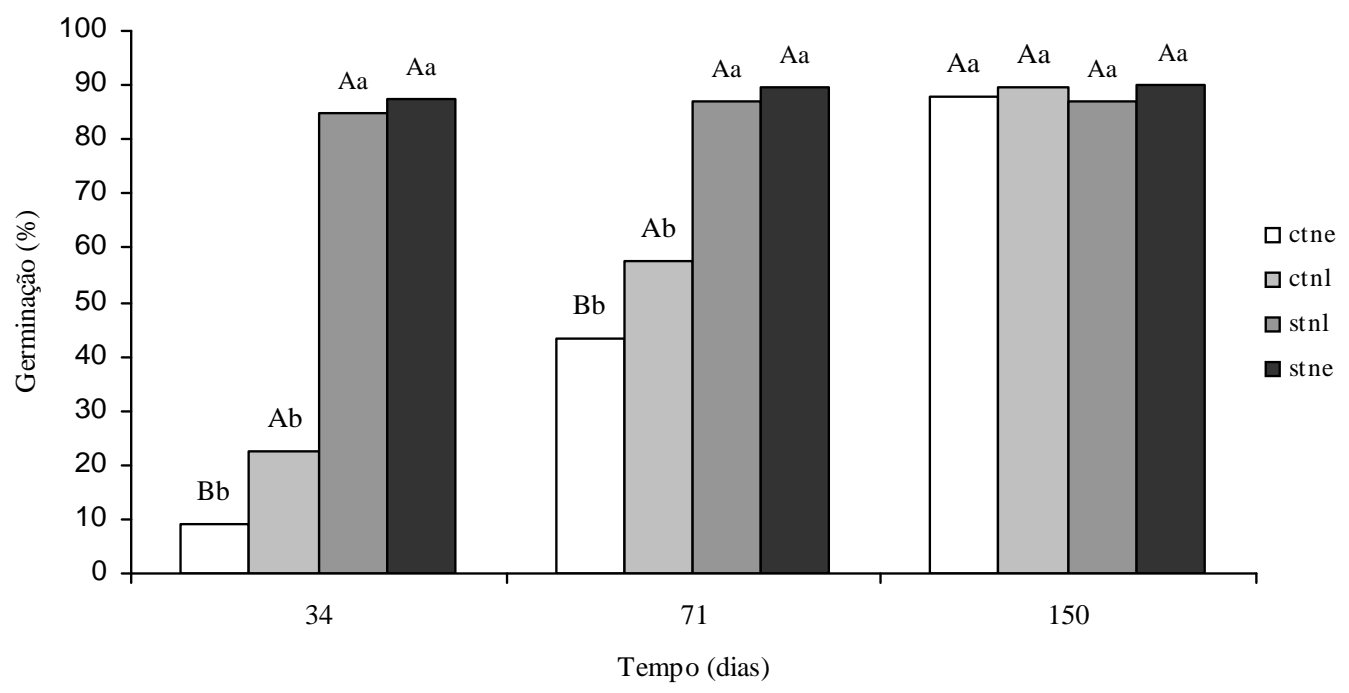

Figura 1 - Interação entre a condição de luz e a retirada do tegumento durante a germinação in vitro de sementes de cagaiteira (ctne - com tegumento no escuro; ctnl - com tegumento na luz; stnl - sem tegumento na luz; stne - sem tegumento no escuro). Médias, para mesma data, seguidas de mesma letra maiúscula (efeito da luz) e minúscula (efeito da retirada do tegumento), não apresentam diferença estatística significativa pelo Teste Scott-Knott, a 5\% de probabilidade.

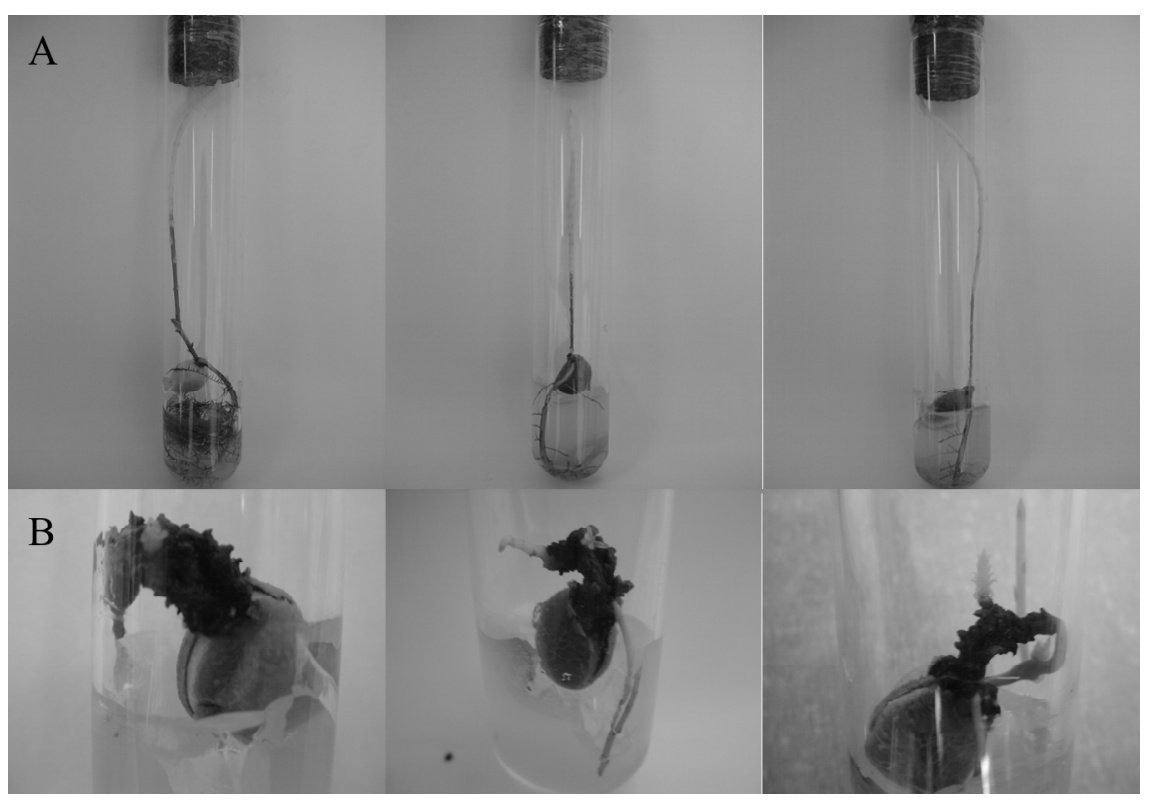

Figura 2 - Plântulas normais (A) e com má formação (B) de cagaiteira provenientes do cultivo in vitro sem e com tegumento, respectivamente.

Ciênc. agrotec., Lavras, v. 31, n. 6, p. 1668-1671, nov./dez., 2007 
Tabela 1 - Quadro de médias da porcentagem de plântulas de cagaiteira germinadas in vitro com má formação quanto à interação entre os tratamentos.

\begin{tabular}{lcc}
\hline Tegumento & Luz & Escuro \\
\hline Presente & $68 \mathrm{Aa}$ & $54 \mathrm{Ab}$ \\
Ausente & $10 \mathrm{Ba}$ & $12 \mathrm{Ba}$ \\
\hline
\end{tabular}

Médias seguidas de mesma letra maiúscula na vertical e minúscula na horizontal não apresentam diferença estatística significativa, pelo Teste Scott-Knott, a 5\% de probabilidade.

Por meio da análise da interação da luz com a retirada do tegumento, quanto à germinação e ao número de plântulas com má formação, pode-se afirmar que o melhor tratamento para a germinação in vitro foi a retirada do tegumento das sementes e a manutenção das mesmas na presença ou na ausência de luz, quando foram verificadas apenas $10 \%$ e $12 \%$ de plântulas com anomalias aos 150 dias de cultivo e $85 \%$ e $87,5 \%$ de germinação aos 31 dias de cultivo, respectivamente. Resultados semelhantes foram apresentados por Coelho (1999), em estudos de germinação de sucupira-branca (Pterodon pubescens (Benth.) Benth.). A autora observou germinação mais rápida e uniforme e maior desenvolvimento posterior da plântula em sementes desprovidas de tegumento em relação às sementes com tegumento seccionado.

\section{CONCLUSÕES}

A escarificação das sementes de cagaiteira cultivadas in vitro proporciona uma germinação mais rápida e uniforme;

A porcentagem de plântulas anormais no cultivo in vitro de sementes de cagaiteira é influenciada pela escarificação e pela luminosidade.

\section{REFERÊNCIAS BIBLIOGRÁFICAS}

ANDRADE, A. C. S.; CUNHA, R.; REIS, R. B.; ALMEIDA, K. J. Conservação de sementes de cagaita (Eugenia dysenterica DC.) Myrtaceae. Informativo ABRATES, Brasília, v. 7, n. 1/2, p. 205, 1997.
COELHO, M. C. F. Germinação de sementes e propagação in vitro de sucupira branca [Pterodon pubescens (Benth.) Benth.]. 1999. 119 p. Dissertação (Mestrado em Fitotecnia) - Universidade Federal de Lavras, Lavras, 1999.

EDWARDS, M. M. Seed dormancy and seed environment internal oxigen relationship. In: HEYDECKER, W. (Ed.). Seed ecology. Miyage-ken: The Pennsylvania State University; University Park, 1973. p. 169-188.

MELO, J. T. de; SILVA, J. A. da; TORRES, R. A. de A.; SILVEIRA, C. E. dos S. da; CALDAS, L. S. Coleta, propagação e desenvolvimento inicial de espécies do cerrado. In: SANO, S. M.; ALMEIDA, S. P. (Eds.). Cerrado: ambiente e flora. Planaltina: Embrapa-CPAC, 1998. p. 195-243.

MURASHIGE, T.; SKOOG, F. A revised medium for rapid growth and bioassays with tobacco tissue cultures. Physiologia Plantarum, Copenhagen, v. 15, n. 3, p. 473497, Mar. 1962.

RIZZINI, C. T. Aspectos ecológicos da regeneração em algumas plantas do Cerrado. In: SIMPÓSIO SOBRE O CERRADO, 3., 1971, São Paulo, SP. Anais... São Paulo: E. Blucher, 1971. p. 61-64.

RIZZINI, C. T. Efeito tegumentar na germinação de Eugenia dysenterica DC. (Myrtaceae). Revista Brasileira de Biologia, Rio de Janeiro, v. 30, n. 3, p. 381-402, set. 1970.

TIBURTIUS, E. R. L. Remediação de água contaminadas por BTX's utilizando processos oxidativos avançados. 2004. Dissertação (Mestrado) - Universidade Federal do Paraná, Curitiba, 2004.

VON-PINHO, E. V. R.; KIKUTI, A. L.Portal do agronegócio do café: inibidores da germinação no espermoderma. Disponível em: <http://www.coffeebreak.com.br/ ocafezal.asp?SE=8\&ID=228>. Acesso em: 25 jul. 2004.

ZIOLLI, R. L.; JARDIM, W. F. Mecanismo de fotodegradação de compostos orgânicos catalisada por tio2. Química Nova, São Paulo, v. 21, p. 319-325, 1998. 